JRPB, Vol. 7, No. 2, September 2019, Hal. 157-165

DOI: $10.29303 / \mathrm{jrpb} . v 7 \mathrm{i} 2.117$

ISSN 2301-8119, e-ISSN 2443-1354

Tersedia online di http://jrpb.unram.ac.id/

\title{
PENENTUAN LIKU KALIBRASI DEBIT (RATING CURVE) PADA MUSIM HUJAN DI DAERAH ALIRAN SUNGAI (DAS) DELI
}

\section{Determination Of Discharge Rating Curve On Rainy Season In Deli Watersheds}

\author{
Andi Setiawan ${ }^{1 *}$, Edi Susanto1 \\ ${ }^{1}$ Program Studi Keteknikan Pertanian, Fakultas Pertanian, Universitas Sumatera Utara \\ Jl. Prof. Dr. A. Sofyan No. 3 Kampus USU Medan 20155 \\ Email ${ }^{*}$ : andisetiawan111216@gmail.com
}

Diterima: Juli 2019

Disetujui: September 2019

\begin{abstract}
Discharge rating curve is a curve that shows the relationship between water level and river discharge so that it can be used to predict the magnitude of discharge in the river. The purpose of this research was to obtain the equation of the discharge rating curve in the Deli watershed. This research was conducted by measuring river water discharge and taking water level data using a water level logger with observations at least twice a week. River water discharge at the study site has a variable value of $0,74-3,28 \mathrm{~m}^{3} / \mathrm{sec}$ with an average of $1,06 \mathrm{~m}^{3} / \mathrm{sec}$. The determination of the discharge rating curve equation is using several methods namely linear, polynomial, power function, logarithmic, and exponential. The results of the study showed that the equation with the second order polynomial method has the best level of correlation $(r)$ and RMSE with value $r$ of 0.986 and RMSE 0.010 and obtained a coefficient of determination $\left(R^{2}\right)$ the discharge rating curve equation at the research location was 0,972, meaning that river flow that occurred $97 \%$ was influenced by the water level factor. The greater the water level, the higher the discharge will be. The rating curve equation obtained was $Q=$ $18,97(h)^{2}-1,372(h)+0.190$.
\end{abstract}

Keyword : discharge, water level, watershed, discharge rating curve

\begin{abstract}
ABSTRAK
Liku kalibrasi debit merupakan kurva yang menunjukkan hubungan antara tinggi muka air dan debit sungai sehingga dapat digunakan untuk memprediksi besarnya debit pada sungai tersebut. Tujuan penelitian ini adalah untuk mendapatkan persamaan liku kalibrasi debit di DAS Deli. Penelitian ini dilakukan dengan mengukur debit air sungai dan mengambil data tinggi muka air menggunakan alat water level logger dengan pengamatan minimal dua kali dalam seminggu. Debit air sungai pada lokasi penelitian memiliki nilai yang bervariasi yaitu $0,74-3,28 \mathrm{~m}^{3} /$ detik dengan rata-rata $1,06 \mathrm{~m}^{3} /$ detik. Penentuan persamaan liku kalibrasi debit menggunakan beberapa metode yaitu linier, polinomial, berpangkat, logaritmik, dan eksponensial. Hasil dari penelitian diperoleh
\end{abstract}


bahwa persamaan dengan metode polinomial orde dua memiliki tingkat korelasi (r) dan RMSE yang terbaik dengan nilai $r$ 0,986 dengan nilai RMSE sebesar 0,010 dan diperoleh nilai koefisien determinasi $\left(\mathrm{R}^{2}\right)$ persaman garis lengkung debit pada lokasi penelitian sebesar 0,972, artinya debit sungai yang terjadi $97 \%$ dipengaruhi faktor tinggi muka air. Semakin besar tinggi muka airnya, maka debit yang terjadi akan semakin tinggi. Persamaan rating curve yang diperoleh adalah $\mathrm{Q}=18,97(\mathrm{~h})^{2}-1,372(\mathrm{~h})+0,190$.

Kata kunci: debit, tinggi muka air, daerah aliran sungai, liku kalibrasi debit.

\section{PENDAHULUAN}

\section{Latar Belakang}

Daerah Aliran Sungai (catchment area, watershed) adalah suatu wilayah daratan yang merupakan satu kesatuan dengan sungai dan anak - anak sungainya, yang berfungsi menampung, menyimpan, dan mengalirkan air yang berasal dari curah hujan ke danau atau ke laut secara alami, yang batas di darat merupakan pemisah topografis dan batas di laut sampai dengan daerah perairan yang masih terpengaruh aktivitas daratan (Wismarini dkk., 2011).

Debit aliran dapat dijadikan sebuah tolak ukur untuk memonitor dan mengevaluasi neraca air suatu kawasan melalui suatu pendekatan potensi sumber daya air permukaan yang ada. Perhitungan debit air bertujuan untuk mengetahui kapasitas DAS disuatu kawasan untuk melakukam analisis sistem drainase pada saluran drainase primer dan sekunder (Neno dkk., 2016).

Salah satu komponen hidrologi yang sangat penting dalam penyelesaian masalah hidrologi suatu DAS adalah data debit sungai yang akurat. Namun masalah yang terjadi di DAS Deli pada saat ini adalah tidak tersedianya data debit aliran sungai (DAS) Deli, hal ini dikarenakan adanya beberapa faktor seperti faktor waktu pengamatan data yang relatif sedikit, faktor biaya yang mahal, faktor alat yang tidak terkalibrasi dengan baik serta resiko dalam pengambilan data. Oleh karena itu untuk melengkapi data yang tidak tersedia maka dilakukan pengambilan data secara langsung di stasiun pengukuran arus sungai (SPAS) sehingga data tersebut dapat mewakili data debit air pada musim hujan maupun kemarau pada DAS Deli.

Untuk mendapatkan data debit DAS Deli yang akurat dan lengkap maka perlu dilakukan penelitian agar data debit sungai Deli dapat diketahui dan dapat digunakan oleh instansi terkait dalam menanggulangi besarnya debit pada musim hujan. Salah satu model pendugaan debit sungai adalah persamaan liku kalibrasi (Rating Curve) yang merupakan persamaan garis yang menghubungkan tinggi muka air sungai (m) dengan besanya debit aliran, sehingga dapat diduga melalui ukuran tinggi muka air.

\section{Tujuan}

Adapun tujuan dari penelitian ini adalah untuk mendapatkan persamaan rating curve hubungan antara tinggi muka air sungai dengan debit sungai di daerah aliran sungai (DAS) Deli pada musim hujan.

\section{Manfaat Penelitian}

Persamaan Liku Kalibrasi (Rating Curve) dapat digunakan stakeholder atau pengelola DAS Deli untuk menghitung besarnya debit pada suatu DAS hanya dengan mengetahui data tinggi muka air dan dapat digunakan sebagai bahan pertimbangan dalam penentuan besaran debit. 


\section{METODE PENELITIAN}

\section{Alat dan Bahan}

Alat yang digunakan dalam penelitian ini adalah ArcGIS ver 10.1, untuk deliniasi DAS, Software Hydroclimatology untuk membaca data hujan yang telah terisimpan oleh alat Automatic Rainfall Logger merk Tatonas, Software Global Logger II untuk membaca data tinggi muka air (TMA) yang telah terisimpan oleh alat Automatic Water Level Logger merk Global Water, Peta jenis tanah dan peta tutupan lahan, stopwatch untuk menghitung waktu kecepatan aliran sungai, meteran untuk menghitung panjang dan lebar sungai, pelampung untuk mendapatkan data kecepatan aliran air.

Bahan-bahan yang digunakan pada penelitian ini yaitu data debit sungai, data tinggi muka air, data curah hujan dan data sifat fisik tanah.

\section{Metode}

Penelitian ini menggunakan metode deskriptif dengan survei lapangan, pengamatan langsung di lapangan dan analisa tanah dilakukan di Laboratorium Riset dan Teknologi Fakultas Pertanian Universitas Sumatera Utara. Penelitian ini menggunakan data primer dan data sekunder. Pembuatan kurva lengkung debit (rating curve) merupakan hubungan debit dan tinggi muka air sungai menggunakan logarithmic, linier, power function, exponensial dan polynomial. Evaluasi model yang digunakan adalah koefisien determinasi, koefisien kolerasi, dan root mean square error (RMSE).

Penelitian ini dilakukan melalui 5 tahap yaitu penentuan lokasi (outlet), pemasangan alat water level logger dan rainfall logger, pengumpulan data primer dan skunder, penentuan persamaan rating curve, dan evaluasi model.

Tahap pertama merupakan penentuan lokasi penelitian, lokasi ditetapkan di bagian hulu DAS Deli yaitu tepatnya di Sub DAS Sei Petani. Sub DAS Sei Petani dipilih sebagai lokasi penelitian karena pada sub DAS tersebut sudah terpasang alat pengukur tinggi muka air secara otomatis (water level logger) dan penakar hujan secara otomatis (rainfall logger).

Tahap kedua yaitu pemasangan alat water level logger dan Automatic rainfall logger. Alat tersebut dipasang disekitar badan sungai Sub DAS Sei Petani. Alat Automatic Water Level Logger dan Automatic rainfall logger dipasang di sisi badan sungai yang kemudian alat tersebut disimpan didalam bangunan permanen di sekitar badan sungai.

Tahap ketiga yaitu pengumpulan data penelitian terdiri atas data primer dan data sekunder. Data primer yang diperlukan antara lain berupa data curah hujan, debit, tinggi muka air, dan sifat fisik tanah. Data skunder yang diperlukan berupa peta DEM yang berfungsi untuk mendapatkan peta lokasi penelitian, peta jenis tanah serta peta tutupan lahan di daerah Sub DAS sei Petani. Untuk memperoleh data debit sungai di titik outletnya maka diukur luas penampang basah dan kecepatan aliran sungai dengan metode pelampung, pelampung yang digunakan untuk mengukur kecepatan aliran adalah bahan yang dapat terapung di permukaan air (SNI, 2015). Masing-masing data tersebut dikumpulkan selama 50 kali pengamatan lalu dihitung dengan rumus :

$\mathrm{Q}=\mathrm{A} \times \mathrm{V}$

dimana:

$\mathrm{Q}=$ Debit aliran $\left(\mathrm{m}^{3} / \mathrm{s}\right)$;

$\mathrm{A}=$ Luas penampang vertikal $\left(\mathrm{m}^{2}\right)$;

$\mathrm{V}=$ Kecepatan aliran sungai $(\mathrm{m} / \mathrm{s})$

Data tingi muka air diperoleh dari water level logger setiap 30 menit secara otomatis dan data curah hujan harian mulai bulan Juli - November 2018 diperoleh dari rainfall logger yang berada di dekat Stasiun Pengukur Arus Sungai (SPAS) Doulu.. Karakteristik fisik dan 
kimia tanah yang digunakan yaitu tekstur tanah, bahan organik dan kerapatan massa yang dilakukan di Laboratorium Riset dan Teknologi Fakultas Pertanian Universitas Sumatera Utara.

Tahap keempat yaitu membuat rating curve dengan menggunakan beberapa model persamaan seperti linier, eksponensial, logaritmik, berpangkat (power function) dan polinomial.

Tahap kelima yaitu evaluasi model yang bertujuan untuk mengetahui seberapa baik model persamaan tersebut jika dibandingkan dengan data observasi. Evaluasi model ini menggunakan koefisien determinasi $\left(\mathrm{R}^{2}\right)$, koefisien kolerasi dan root mean square error (RMSE). Perhitungan RMSE menggunakan rumus:

RMSE $=\sqrt{\frac{\sum_{\mathrm{i}=1}^{\mathrm{n}}\left(\mathrm{y}_{\mathrm{i}} \mathrm{-y}\right)^{2}}{\mathrm{n}}}$

dimana :

yi $=$ nilai observasi

$\mathrm{y}=$ nilai model

$\mathrm{n}=$ jumlah data (Fahmi dkk., 2017).

\section{HASIL DAN PEMBAHASAN}

\section{Kondisi Umum Lokasi Penelitian}

Penelitian ini dilaksanakan pada bulan Juli sampai dengan November 2018. Lokasi penelitian terletak pada $03^{0}$

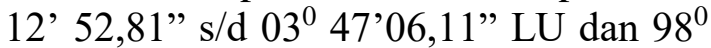
29' 23,32” s/d $98^{0} \quad 42$ ' 49,79" BT, (Gambar 1a) yang merupakan bagian hulu sub DAS Sei Petani (DAS Deli) Kabupaten Karo, Provinsi Sumatera Utara.

Sub DAS Sei Petani memiliki luas 1191 Ha sehingga termasuk kedalam kategori DAS sangat kecil (Permenhut, 2013) dengan panjang aliran sungai utama 5,7 km, dan dengan persentase tutupan lahan seluruhnya pada Sub DAS Sei Petani berupa hutan lahan kering sekunder dengan luas 719,41 ha atau dengan persentase $60,39 \%$ dari keseluruhan luas daerah Sub DAS Sei Petani, pertanian lahan kering dengan luas 162,19 ha atau dengan persentase 13,61\% dari keseluruhan luas daerah Sub DAS Sei Petani, semak/belukar dengan luas 269,69 ha atau dengan persentase 22,63\% dari keseluruhan luas daerah Sub DAS Sei Petani dan tanah terbuka dengan luas 39,93 ha atau dengan persentase 3,35\% dari keseluruhan luas daerah Sub DAS Sei Petani. Luas tutupan lahan pada Sub DAS Sei Petani dapat dilihat pada peta tutupan lahan (Gambar 1b).

Pada wilayah sekitar SPAS Doulu yang berada di bagian hulu DAS Deli tersebut didominasi oleh dua jenis tanah yaitu andosol dan podsolik. Adapun Jenis tanah dengan luas terbesar didominasi oleh tanah Andosol dengan luas 1028 ha dan podsolik hanya 163 Ha. Tanah andosol dan podsolik yang berada disekitar wilayah SPAS Doulu memiliki tekstur yang berbeda dikarenakan fraksi penyusunnya. Tekstur pasir berlempung untuk tanah andosol dengan kandungan fraksi pasir 79,68\%, fraksi debu $11,72 \%$, fraksi liat $8,60 \%$ sedangkan tekstur lempung berpasir untuk tanah podsolik memiliki kandungan fraksi pasir $77,68 \%$, fraksi debu 11,28\%, fraksi liat $11,04 \%$ (Gambar 1c). 

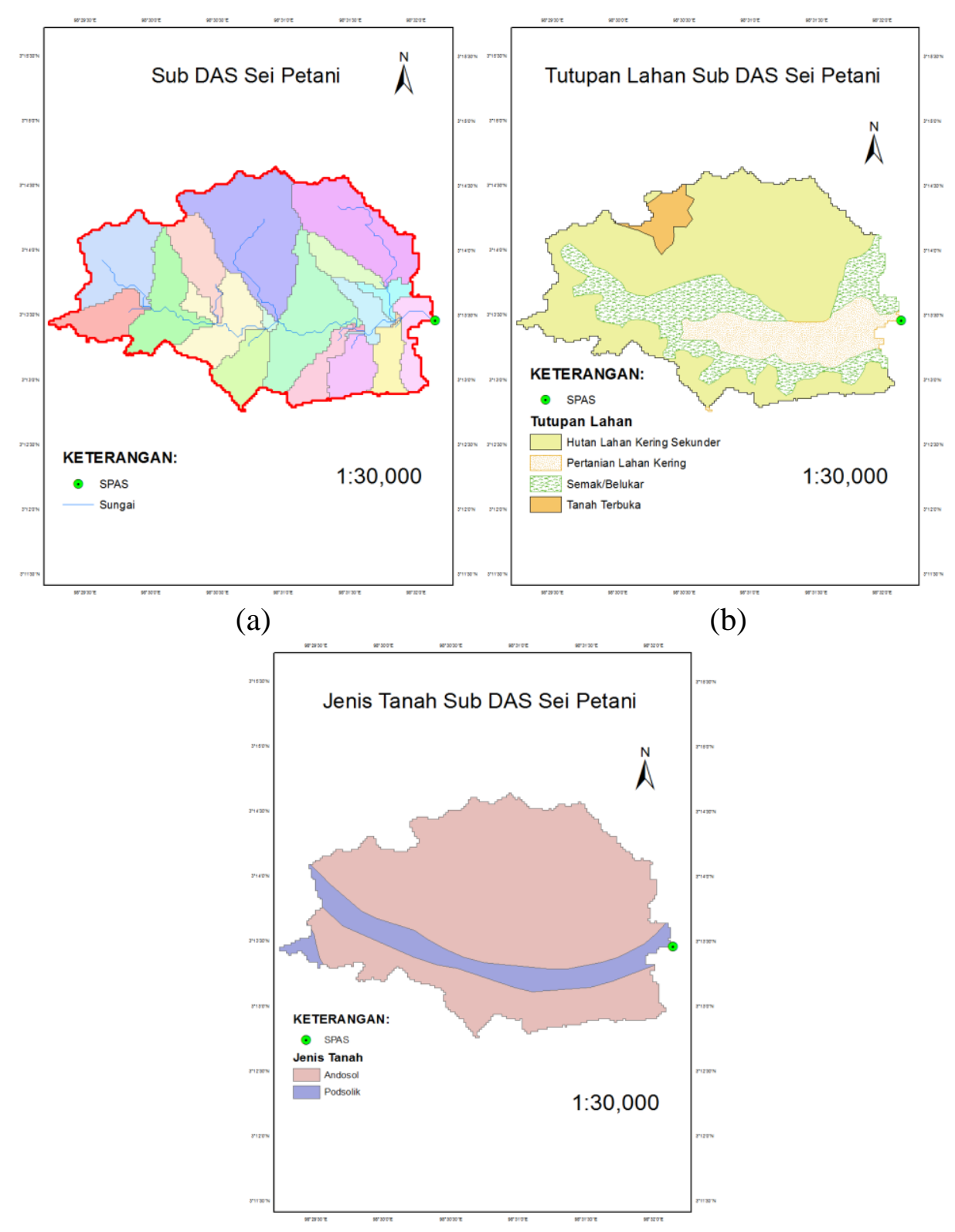

(b)

(c)

Gambar 1. (a) Lokasi Penelitian Sub DAS Sei Petani, (b) Penutup Lahan Sub DAS Sei Petani, (c) Jenis Tanah Sub DAS Sei Petani.

\section{Debit dan Tinggi Muka Air Sungai}

Dalam mencari nilai debit maka diperlukan data primer berupa pengukuran luas penampang basah (A) dan kecepatan aliran (V) serta tinggi muka air sungai. Pada penelitian ini, tinggi muka air dan kecepatan arus diukur di Stasiun Pengamat Arus Sungai (SPAS) yang merupakan bangunan di badan sungai dengan penampang permanen di suatu titik keluaran. Penampang pada Sub DAS Sei Petani tersebut merupakan penampang permanen yang telah dimodifikasi sebagai titik pengamatan oleh BPDAS dengan bentuk trapesium yang memiliki panjang penampang 15 meter dan luas 6 meter. 
Tinggi muka air sungai diukur dengan menggunakan alat ukur tinggi muka air sungai otomatis (Automatic Water Level Recorder). Dari data tinggi muka air sungai ini akan dihasilkan data luas penampang basah secara periodik (Nugroho, 2015). Dari data tersebut maka akan diperoleh nilai debit air sungai dengan menggunakan rumus Persamaan 1.

Data debit DAS Deli pada SPAS Doulu dapat dketahui bahwa nilai debit air sungai memiliki nilai yang bervariasi, yaitu dengan debit terendah sebesar 0,74 $\mathrm{m}^{3} /$ detik dan debit tertinggi sebesar 3,28 $\mathrm{m}^{3} /$ detik dengan rata-rata debit sebesar $1,06 \mathrm{~m}^{3} /$ detik. Variasi debit pada DAS Deli disebabkan oleh tinggi muka air sungai yang terus mengalami perubahan. Perubahan tinggi muka air pada saluran sungai dipengaruhi oleh besar atau kecilnya nilai limpasan air, sebab semakin besar nilai limpasan air maka nilai tinggi muka air akan naik (Linsley dan Franzini, 1991; Neno dkk., 2016).

Besaran nilai debit juga dipengaruhi oleh besarnya intensitas curah hujan pada waktu tertentu. Pada Gambar 2 dapat terlihat bahwa debit air sungai pada SPAS Doulu (DAS Deli) akan mengalami peningkatan ketika curah hujan dengan intensitas yang tinggi dan menurun ketika curah hujan rendah, hal ini terjadi karena pada saat curah hujan tinggi, maka akan terjadi limpasan air permukaan yang besar. Sebagian air limpasan akan terinfiltrasi, namun air yang tidak terinfiltrasi akan mengalir menuju badan sungai.
Dari pengamatan langsung dilapangan dengan melihat data curah hujan yang telah terekam dan tersimpan pada alat Automatic rainfall logger dapat kita lihat pada Gambar 2 bahwa pada bulan juli hingga agustus curah hujan sangat rendah dan hampir tidak terjadi hujan dengan jumlah hujan terendah yang terjadi pada bulan agustus dengan jumlah hujan $1 \mathrm{~mm}$, dan pada bulan september hingga bulan november curah hujan yang didapat menunjukan bahwa pada bulan september telah memasuki musim hujan dengan curah hujan tertinggi terjadi pada bulan oktober dengan jumlah hujan 281 mm. Menurut BMKG (2018), Pada Prakiraan puncak musim hujan 2018/2019 sebagian besar wilayah Sumatera bagian tengah dan utara diprakirakan akan mengalami puncak musim hujan sejak bulan Oktober hingga Desember.

Debit sungai tidak pernah konstan namun selalu berubah menurut iklim dan keadaan biofisik DAS. Dengan mengukur debit sungai, maka kondisi hidrologis suatu daerah aliran sungai (DAS) akan dapat diketahui. Informasi yang diperoleh dari pengukuran debit adalah perbedaan debit tertinggi dan terendah, dan perubahan debit harian. Informasi tersebut dapat menggambarkan kemampuan DAS dalam menyangga kejadian hujan deras. DAS yang baik mampu menampung curah hujan di atas rata-rata sekaligus menyediakan air saat kemarau panjang (Tanika, 2016).

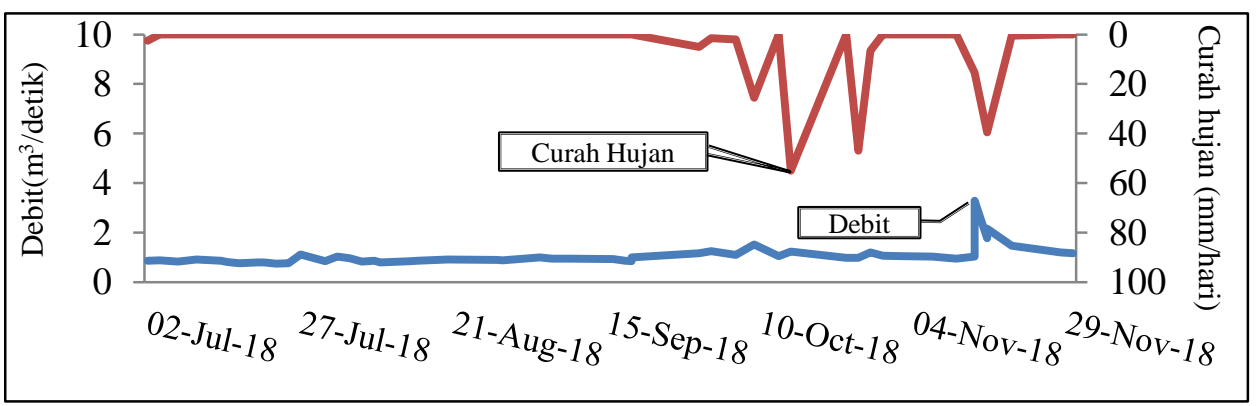

Gambar 2. Hubungan debit dan curah hujan 


\section{Liku Kalibrasi (Rating Curve)}

Dengan menggunakan nilai parameter tinggi muka air dan debit sungai, maka dapat dibentuk kurva liku kalibrasi debit (Gambar 3) dengan menggunakan Persamaan 1.

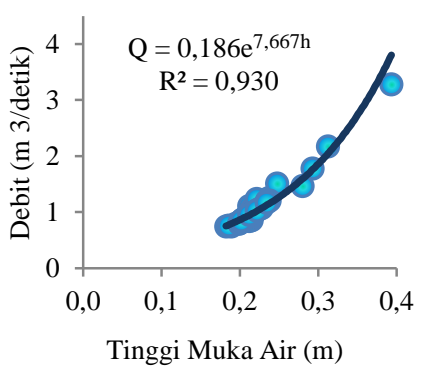

(a)

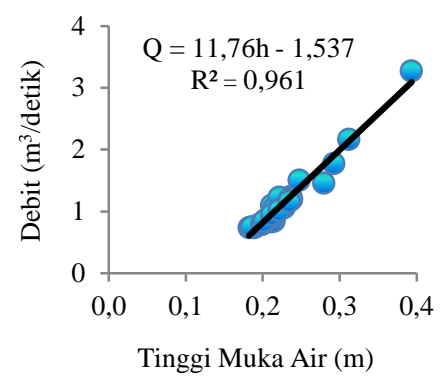

(b)

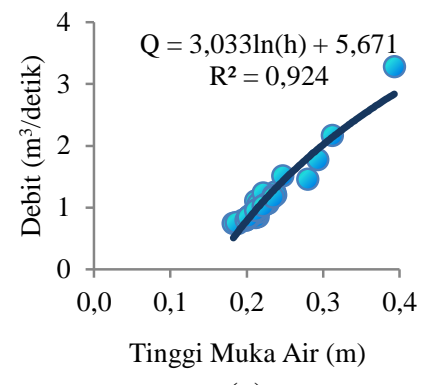

(c)

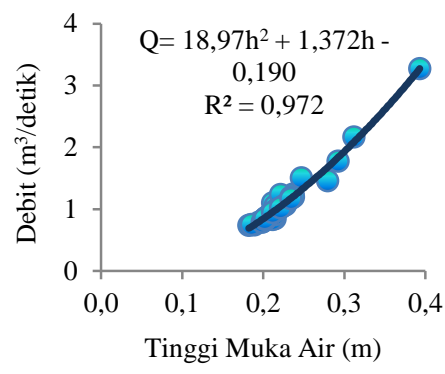

(d)

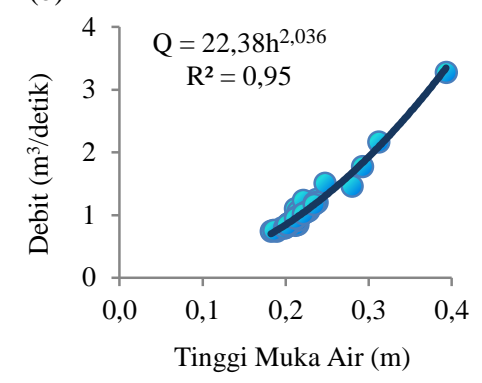

(e)

Gambar 3. Kurva garis lengkung debit dengan (a) metode eksponensial, (b) linier, (c) logaritmik, (d) polinomial, dan (e) berpangkat.

Beberapa alternatif persamaan yang dapat digunakan dalam analisis data hidrologi pada DAS Deli diantaranya adalah model regresi linier sederhana, fungsi berpangkat, fungsi eksponensial, fungsi logaritma dan fungsi polinomial.

Tabel 1. Perbandingan Persamaan Rating Curve dengan Metode Linier, Berpangkat, Eksponensial dan Logaritmik.

\begin{tabular}{|c|c|c|c|c|}
\hline Metode & $\begin{array}{l}\text { Persamaan } \\
\text { Rating } \\
\text { Curve }\end{array}$ & A & B & $\mathrm{C}$ \\
\hline Linier & $\begin{array}{c}\mathrm{Q}=11,76 \mathrm{~h}- \\
1,537\end{array}$ & 11,76 & 1,537 & - \\
\hline Berpangkat & $\mathrm{Q}=22,38 \mathrm{~h}^{2,036}$ & 22,38 & 2,036 & - \\
\hline Eksponensial & $\mathrm{Q}=0,186 \mathrm{e}^{7,667 \mathrm{~h}}$ & 0,186 & 7,667 & - \\
\hline Logaritmik & $\begin{aligned} & \mathrm{Q}= 3,031 \ln (\mathrm{h})+ \\
& 5,671\end{aligned}$ & 3,031 & 5,671 & - \\
\hline Polinomial & $\begin{aligned} \mathrm{Q}= & 18,97 \mathrm{~h}^{2}+1,3 \\
& 72 \mathrm{~h}-0,190\end{aligned}$ & 18,97 & 1,372 & 0,190 \\
\hline
\end{tabular}

Dari persamaan tersebut, yang paling baik yaitu polinomial dengan persamaan sebagai berikut: $\mathrm{Q}=18,97 \mathrm{~h}^{2}+$ $1,372 \mathrm{~h}$ - 0,190 dengan nilai $\mathrm{R}^{2}: 0,972$. 


\begin{tabular}{lll}
\hline Eksponensial & 0,965 & 0,015 \\
Logaritmik & 0,961 & 0,016 \\
Polinomial & 0,986 & 0,010 \\
\hline
\end{tabular}

Berdasarkan hasil perhitungan, Qmodel dengan model polinomial paling mendekati dengan $\mathrm{Q}_{\text {data. }}$ Nilai korelasi (Tabel 2) ini termasuk kedalam tingkat korelasi yang sangat kuat dengan nilai koefisien korelasi tertinggi diantara model lainnya yaitu 0,986 dan nilai RMSE 0,010 maka dianggap bahwa persamaan rating curve yang dihasilkan diatas dapat digunakan untuk menghitung debit. Tingkat korelasi dinyatakan sangat kuat apabila berada pada rentang nilai $0,75<\mathrm{r}<0,99$ (Fahmi dkk., 2017). Persamaan rating curve yang diperoleh adalah $\mathrm{Q}=18,97(\mathrm{~h})^{2}-1,372(\mathrm{~h})+0,190$ untuk selanjutnya persamaan ini dapat digunakan dalam menghitung hidrograf satuan daerah penelitian. Jadi dapat disimpulkan bahwa metode yang tepat untuk membuat lengkung debit adalah model regresi polinomial.

\section{KESIMPULAN DAN SARAN}

\section{Kesimpulan}

Pada penelitian ini dengan menggunakan beberapa model pengkalibrasian antara debit sungai dengan tinggi muka air sungai diperoleh hasil berupa persamaan rating curve dengan model Polinomial merupakan hasil yang terbaik karena memiliki nilai koefisien korelasi (r) yang tertinggi yaitu 0.986 dengan persamaan $\mathrm{Q}=18,97 \mathrm{~h}^{2}+$ 1,372h - 0,190 sedangkan nilai koefisien determinasi $\left(\mathrm{R}^{2}\right)$ dari persaman garis lengkung debit dengan model polinomial sebesar 0,972 , artinya debit sungai yang terjadi $97 \%$ dipengaruhi faktor tinggi muka air.

\section{Saran}

Sebaiknya penelitian dilakukan dengan jangka waktu yang lebih panjang sehingga data yang diperoleh akan lebih baik dan akurat.

\section{Ucapan Terima Kasih}

Pada kesempatan ini penulis mengucapkan terima kasih kepada Lembaga Penelitian Universitas Sumatera Utara atas bantuan biaya yang diberikan melalui skema TALENTA USU dengan

Kontrak No: 2590/UN5.1.R/PPM/2018 dan juga kepada BPDAS Wampu Sei Ular, Sumatera Utara atas bantuan tempat dan peralatannya.

\section{DAFTAR PUSTAKA}

Badan Meteorologi Klimatologi dan Geofisika. (2018). Konferensi Pers Kondisi Cuaca Libur Natal 2018 Dan Tahun Baru 2019. Badan Meteorologi Klimatologi dan Geofisika. Jakarta.

Fahmi, N. M., Suprayogi, I., dan Fauzi, M. (2017). Model Hubungan Antara Tinggi Muka Air-Debit Menggunakan Pendekatan Adaptive Neuro Fuzzy Inference System (ANFIS)(Studi Kasus : Pos Duga AWLR Stasiun Pantai Cermin). Jom FTEKNIK, Vol 4, 1-7.

Linsley, R. K. dan Franzini, J. B. (1991). Teknik Sumberdaya Air. Jakarta: Erlangga.

Neno A.K., Harijanto H, dan Wahid A. (2016). Hubungan Debit Air dan Tinggi Muka Air di Sungai Lambagu Kecamatan Tawaeli Kota Palu. Warta Rimba. Vol 4, 1-8.

Nugroho, H. Y. S. H. (2015). Analisis Debit Aliran Das Mikro dan Potensi Pemanfaatannya. Jurnal Penelitian Kehutanan Wallacea. Vol 4, 23-34.

Badan Standardisasi Nasional 8066. (2015). Tata Cara Pengukuran Debit Aliran Sungai dan Saluran Terbuka Menggunakan Alat Ukur Arus dan 
Pelampung. Badan Standarisasi Wismarini, T. D., Ningsih D. H. U., dan Nasional 8066. Jakarta. Amin F. (2011). Metode Perkiraan Laju Aliran Puncak (Debit Air) sebagai Dasar Analisis Sistem Drainase di Daerah Aliran Sungai Wilayah Semarang Berbantuan SIG. Jurnal Teknologi Informasi DINAMIK. Vol 16, 124-132. 